\title{
Einladung zur Mitgliederversammlung der DRG am Freitag, den 31. Mai 2019
}

Zur ordentlichen Mitgliederversammlung der Deutschen Röntgengesellschaft - Gesellschaft für Medizinische Radiologie e. V. (DRG), am Freitag, den 31. Mai 2019, von 07:30 - 09:15 Uhr im Congress Centrum Leipzig (CCL) im Raum Röntgen, lädt der Vorstand der DRG die Mitglieder der DRG hiermit herzlich ein.

\section{Tagesordnung}

- TOP 1 Feststellung der Beschlussfähigkeit Der Vorstand bittet zu beachten, dass die Mitgliederversammlung gemäß $§ 10$ Abs. 5 der Satzung nur beschlussfähig ist, wenn mindestens 5 Prozent der Mitglieder anwesend sind. Wenn eine Stunde nach Beginn der Versammlung die Beschlussfähigkeit nicht festgestellt werden kann, löst der Versammlungsleiter die Mitgliederversammlung auf und beruft unverzüglich und ohne Frist eine neue Mitgliederversammlung ein. Diese ist ohne Rücksicht auf die Zahl der erschienenen Mitglieder beschlussfähig. Für eine etwaige zweite Mitgliederversammlung gilt die Folge der nachstehen- den Tagesordnungspunkte als Tagesordnung entsprechend.

- TOP 2 Begrüßung

- TOP 3 Totengedenken

- TOP 4 Genehmigung des Protokolls der Mitgliederversammlung vom 10. Mai 2018 (veröffentlicht im Jahresbericht 67, Januar 2019)

- TOP 5 Bericht des Präsidenten

- TOP 6 Bericht des Schatzmeisters

- TOP 7 Bericht der Kassenprüfer

- TOP 8 Entlastung des Vorstands

- TOP 9 Vorschläge für Ehrungen 2020

- TOP 10 Wahl der Kassenprüfer 2020

- TOP 11 Beschluss über die Neufassung der Satzung

Der Vorstand bittet zu beachten, dass eine Darstellung der bisherigen und der neu zu fassenden Satzung aus Gründen der Praktikabilität dieser Einladung nicht in Papierform beigefügt ist. Die Darstellung steht unter der URL https://www. drg.de/de-DE/2772/mitgliederversammlung-2019/ zum Download über den Mitgliederbereich der Deutschen Röntgengesellschaft zur Verfügung, kann auf Wunsch elektronisch versandt werden und liegt in Papierform zu Beginn der Mitgliederversammlung aus.

- TOP 12 Wahl des Vorstands für die Amtsperiode Röntgenkongress 2019 2021

- TOP 13 Wahl des Präsidenten für die Amtsperiode Röntgenkongress 2021 2023

- TOP 14 Wahl des Kongresspräsidenten 2022

- TOP 15 Einladung zum Röntgenkongress 2020

- TOP 16 Verschiedenes

Die Einlasskontrolle erfolgt über den Kongressausweis. Entsprechend der Satzung der DRG können an der Mitgliederversammlung nur Mitglieder teilnehmen, deren Beitragskonto für 2019 ausgeglichen ist.

Im Namen des Vorstands Prof. Dr. Stefan O. Schönberg (Präsident) 